\title{
HEART SIZE AND HEART FUNCTION IN CHILDREN SHOWING ORTHOSTATIC ALBUMINURIA: AN ORTHODIAGRAPHIC STUDY *
}

\author{
MURRAY H. BASS, M.D., AND H. WESSLER, M.D. \\ NEW YORK
}

The close relationship of orthostatic albuminuria to the cardiovascular system has frequently been emphasized, yet in a consideration of the literature one is struck by the diversity of opinions and the contrary findings of various authors. Having at our disposal the material of a large pediatric clinic and noting how frequently cases of orthostatic albuminuria presented themselves for treatment, we determined to study the hearts and blood-pressures in a number of these patients in order to see which of the previous findings we could corroborate, and also whether in the course of our work we could throw some light on the pathogenesis of these symptoms.

The present paper will deal only with our results in the examination of the heart, and we leave a consideration of the blood-pressures to a future communication.

Ever since Edel ${ }^{1}$ called attention to the cardiovascular factor as an important one in the etiology of orthostatic albuminuria, many observations have been made, both on the heart and the vessels, in an attempt to clear up this obscure subject. Although various investigations have not as yet been able to solve the problem, nevertheless in their course a considerable amount of interesting data has been brought forward. At first there was a tendency to explain the albuminuria purely as the result of a cardiovascular abnormality, but it soon became clear that urine of a similar character was excreted by children in whom no physical abnormalities could be detected. On the other hand, it had been noted that a large number of children who showed this urinary anomaly also presented cardiovascular peculiarities. These symptoms appeared to be more or less characteristic, and led Langstein ${ }^{2}$ to classify his cases of orthostatic albuminuria in three groups: 1 . Children who have grown rapidly, who complain of fatigue, palpitation and headache, look pale, but whose hemoglobin is normal. This type usually occurring in girls of 12 to 14 years, Langstein terms the angiospastic type. 2. Children

* Submitted for publication in The ARchives, Dec. 27, 1912.

* From the Dispensing and $X$-Ray Departments of Mt. Sinai Hospital.

1. Edel: Mtinchen. med. Wchnschr., 1901, Nos. 46 and 47.

2. Langstein: Die Albuminurien älterer Kinder, Monograph, Leipzig, 1907. 
who flush easily, who show marked vascular irritability, whose complaints are chiefly congestive headaches, vomiting attacks and urticaria. These cases he groups as the erethic type. 3. Children whose physical examination shows no abnormality and who have no complaints. In such cases the albuminuria is incidentally found in a routine examination.

It appears, therefore, both from previous observations and from the cases we are about to describe, that when subjective symptoms do occur in orthostatic albuminuria they are chiefly those referable to the cardiovascular system, viz., dyspnea on exertion, palpitation, precordial pain, headache, fainting, hypersusceptibility to cold. These symptoms, coming on as a rule in children between the ages of 10 and 14, have become intimately associated with the symptomatology of puberty. This connection has long been noted, and has led to numerous hypotheses in which a disproportion between the growth of the various organs and the work they are called on to perform at this period of rapid bodily development has been assumed as the basis of these symptoms. An analogy is seen between the albuminuria, which is supposedly due to an insufficiency of the kidney, unable in its growth to keep pace with the rest of the body, and the cardiac symptoms which are an expression of a similar developmental backwardness of the heart.

The material on which this report is based comprises thirty-six dispensary cases, who during the previous fourteen months applied for treatment for a variety of complaints. These complaints, coupled with the more or less characteristic appearance of the children, led us to suspect albuminuria. In each case albumin was shown to be present in the urine by the addition of dilute acetic acid and the application of heat. The albuminuria was then proved to be of the orthostatic variety by the examination of several specimens of the early morning urine, which was found to be albumin free. In a few of the cases albumin only appeared in the urine after the child was placed in the lordotic position by kneeling as described by Jehle. ${ }^{3}$ In all the cases the albumin disappeared on the assumption of the horizontal position. In none of the cases were casts found, though centrifuged specimens of the urine were frequently examined, some of them over a period of a year. These cases were subjected to a functional heart examination in the following manner:

A complete physical examination of each child was made in such a manner that the element of fear or nervousness on the part of the child could be excluded as much as possible. Then on another day the heart size was determined by orthodiagraphy in the sitting posture and the pulse-rate taken. The child was next made to run up and down four flights of stairs rapidly and was then immediately orthodiagraphed a second time and the pulse again counted. The fluoroscopic examination was always done at the same time of the day, sufficiently removed from meal-time to obviate sources of error. The orthodiagraph was in every case made by the same one of us and the physical examination by the other so that the personal element might be eliminated.

3. Jehle: Die Lordotische Albuminurie, Leipzig and Wien, 1909. 


\section{EXAMINATION OF THE HEART AT REST}

In Table 1 will be found the results of the orthodiagraphic examination of these thirty-six children while at rest. In the fifth column are given the average figures of heart size for children of corresponding heights as determined by Veith." A comparison of these figures shows seven of the hearts to be larger than normal. Of these seven cases, six show an increase over the normal of but 1 to $3 \mathrm{~mm}$., differences within the limits of error. This leaves one case (Case 18) in which the heart is distinctly enlarged. Of the remaining twenty-nine cases, twenty-two show values lower than the normal. It is remarkable that the majority of these figures differ from the normal by relatively large amounts from 1 to $4 \mathrm{~cm}$. In this chart we have included all our cases of ortbostatic albuminuria irrespective of the presence or absence of cardiac symptoms. Included in these, however, are fifteen children who either complained of subjective symptoms or presented signs of cardiac abnormality on physical examination. It is, therefore, of interest to determine whether these fifteen can be differentiated from the others in respect to heart size. This is of especial importance in view of the effort which has been made by investigators for some years to find in an alteration in heart size and function an explanation of these very symptoms.

French and German clinicians have advanced various theories to explain these symptoms. ${ }^{5}$ As has been mentioned above, it appeared to most observers that since many of these cases occurred at or immediately before puberty, owing to a lack of correspondence of growth between the heart and the body, a relative insufficiency of the former became manifest, accentuated by the excessive psychical and physical demands of the growing body. This weakness showed itself, especially in children, who by heredity or environment, were handicapped by poor physical development. The ensuing malnutrition also expressed itself in poorly developed hearts, with the results that the demands of even every-day life were the cause of subjective and objective signs of heart insufficiency, such as in normal individuals would be manifest only after considerable exertion. To quote Martius" : "Heart weakness without expressly discoverable cause, brought about by the ordinary demands of life, incidental to the school age." The same idea has been aptly expressed by Fairbanks, who, in speaking of the "Essential Insufficiency of the Heart in Childhood," says: "One reason why the aggregate of demands on the heart may sometimes exceed its power to respond lies in the fact that the general bodily development is neither synchronous nor symmetrical."

4. Veith: Pahrb. f. Kinderh., 1908, lxviii, 205.

5. Lommel: Krankheiten des Jünglingsalters, Ergeb. d. inn. Med. u. Kinderh., 1910 , vi.

6. Martius: Kongress f. inn. Med., 1899, p. 41.

7. Fairbanks: Jour. Am. Med. Assn., 1907, xlix, 1976. 
This clinical picture, to which Germain Sée ${ }^{8}$ first called attention in 1889 , and to which he gave the name "Hypertrophie et dilatation de la croissance," was further developed and more completely described by Martius. ${ }^{9}$ In the examination of a large number of institution children this observer was impressed by the existence of a distinct group presenting the following typical appearance:

The children are weak, pale, lose their appetite, complain of headache. . . . Examination reveals besides slight enlargement of the cervical nodes, moderate anemia, sometimes but not always orthostatic albuminuria, the absolutely characteristic heart finding-dilatative weakness.

According to Martius, in this condition the physical signs are characteristic. The apex-beat of the heart is displaced beyond the nipple, sometimes out as far as the anterior axillary line; it is heaving in character; the pulse shows distinct diminution in tension and has a tendency after exercise to increase in rate out of all proportion to the amount of the exertion and at the same time to become very poor in quality. This condition Martius considers frequent among the poorer classes.

While during the past decade orthostatic albuminuria was arousing considerable interest ${ }^{10}$ and the children suffering from it were subjected to careful study, it became apparent that a great number of them belonged to the above group described by Martius, the albuminurics showing eardiac signs and symptoms identical with those classed as dilatative weakness. Thus in ninety cases of orthostatic albuminuria Lommel ${ }^{11}$ found thirty-eight with cardiac abnormalities, thirteen with apparent left ventricle hypertrophy, elever with markedly exaggerated apex-beat and nine with systolic murmurs. Schaps ${ }^{12}$ in the same way notes a big percentage of enlarged hearts with subjective symptoms. The idea was, therefore, generally accepted that many orthostatic albumiurics had cardiac enlargement. It must be remembered, however, that these observations were made before the introduction of the more precise methods of examination afforded by the $x$-rays, and it is therefore of considerable interest to find that when a few similar cases were subjected to fluoroscopic examination no enlargement of the heart was found. Fisch ${ }^{13}$ who skiagraphed these hearts found them normal, while Langstein and Reyher, ${ }^{2}$ using the orthodiagraph, found to their surpise that in eight cases so examined the hearts were smaller than usual. This

8. Germain Sée: Traite des maladies du coeur. 1889.

9. Martius: Loc. cit. Note 6, and Gedenkschrift für von Leuthold, 1906.

10. For a review of the latest literaturo on this subject see Bass: A Summary of the Recent Literature on Orthostatic Albuminuria. Am. Jour. Dis. Child, 1912 , iv, 246.

11. Lommel: Arch. f. klin. Med., 1903, No. 78, p. 540.

12. Schaps: Arch. f. Kinderh., 1903, No. 35.

13. Fischl: Arch. f. Kinderh., 1909, lii. 
Table 1.-Heart Size During Rest in Thirty-Six Cases of Orthostatic albuminuria; Twenty-Six Girls and Ten Bors*

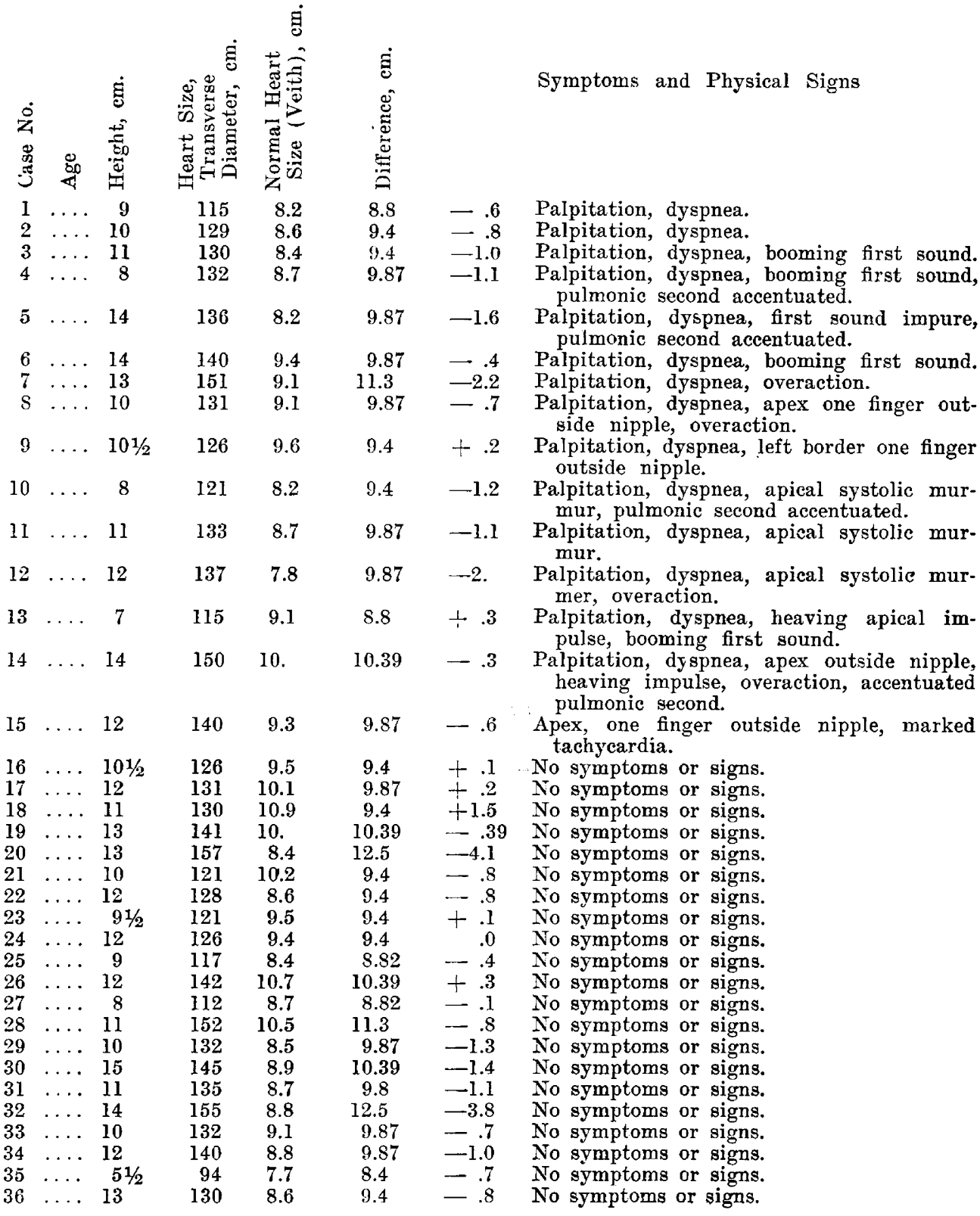

*The first fifteen cases in this table are those in which symptoms or physical signs of cardiac abnormality were present. The remainder were free from such signs. 
discrepancy, though in so small a number of cases, is important enough to deserve further investigation.

Returning once more to our own cases, we have placed the children who show either subjective or objective signs of cardiac involvement together at the commencement of Table 1. (Cases 1 to 15.) In the last column are enumerated the corresponding signs and symptoms.

A study of these fifteen cases shows that in none of them is the heart increased in size. Two of them reveal an increase over the normal of 2 and $3 \mathrm{~mm}$., respectively, values which, as was mentioned above, are within the limits of error. On the other hand, nine of the remaining show a distinctly small heart, differing in one case by as much as 22 $\mathrm{mm}$. from the normal size. The hearts are enlarged neither to percussion nor to fluoroscopy, with four exceptions (Cases 8, 9, 14 and 15), in which percussion showed slight enlargement to the left, which was verified, however, by the orthodiagraph only in one instance. The significance of the enlargement in this case (Case 9) will be discussed later. Our results are, therefore, in accord with the observations of Langstein, Reyher and Fischl, who found no enlargement.

In spite of the absence of any demonstrable increase in the size of the hearts, all of these children nevertheless had definite symptoms. They commonly complained of dyspnea on exertion, of palpitation, or more rarely, of precordial pain. Twelve of the fifteen had definite signs of abnormal function; five had booming first sound; three had apical systolic murmurs; four had marked accentuation of the second pulmonic sound; four showed apical signs of marked over-action and four showed increase of heart dulness to the left. These are all distinct signs and symptoms of relative heart insufficiency, and undoubtedly correspond to the cases described by Martius and others as dilatative weakness.

It may not be amiss at this point to present in detail the history and physical examination of one of our cases:

History.-R. P. (Case 8), female of Russian parentage, aged 10 years.

Family History.-An older sister has rheumatic endocarditis for which she has been in the hospital on several occasions. Parents well. No history of tuberculosis.

Past History.-Measles in early childhood. Except for several mild attacks of tonsillitis the child has been well. Has never had scarlet fever.

Present Illness.-For the past ten months the patient has noted epigastric oppression, severe dyspnea and palpitation on exertion. No cough. No sweats. No edema. No fever. Does not vomit. Appetite fair. Bowels regular. Sleeps well.

Physical Examination.-A very nervous child, showing poor muscular tonus, as evidence of which there is a marked exaggeration of the lumbar lordosis. Marked pallor of the skin, but lips and mucous membranes strikingly ruddy. Hands cold and cyanotic. Marked dermographia. Chvostek's sign positive.14

14. For the value of this sign see Bass, "Chvostek's Sign and Its Significance in Older Children," Am. Jour. Med. Sc., July, 1912. 
Mouth, throat, Jymph-nodes, eyes negative. Chest Iong and flat; scapulae winged: epigastric angle narrow. Lungs negative. Heart: Apex in the fifth space in the nipple line; distinct over-action; percussion shows the left border one finger outside the nipple line; first sound at apex booming in character; no murmurs; second sounds at base accentuated; action regular, somewhat rapid; short venous hum over the vessels of the neck; pulses regular; no increased tension. Abdomen lax; right kidney palpable.

Orthodiagraphy reveals a heart normal in shape, size and position.

Urine: A. M. specimen albumin-free; p. m. specimen, faint trace of albumin; after lordosis (kneeling for three minutes), very heavy precipitate of albumin.

This case, then, presents the typical picture we have above describeda child who comes to us complaining of severe palpitation and dyspnea on exertion, who is suffering from orthostatic albuminuria, whose physical examination by the ordinary methods would lead one to suspect cardiac enlargement. However, in spite of the signs of cardiac over-action and the fact that percussion shows the heart dulness one finger to the left of the nipple, careful measurement with the orthodiagraph proves that the heart is normal in size and position.

It may be concluded from our findings that the conception "dilatative weakness" as applied to cases of orthostatic albuminuria, at least in so far as it assumes enlargement of the heart, is a mistaken one, due probably to errors in percussion, which will be discussed later on. Nor can the small hearts stand in a causative relation to these symptoms, since the smallest heart sizes were found among those children who did not present any symptoms at all.

\section{EXAMINATION OF HEAR'T SIZE AFTER EXERTION}

Having definitely decided that these hearts during rest were normal or under-sized, the next question to be determined was what alteration in size, if any, the heart underwent after exercise.

The change in size in the normal heart after exertion has been thoroughly studied by numerous observers since the introduction of precise methods for the determination of heart size. Moritz, ${ }^{15}$ Dietlen, ${ }^{16} \mathrm{Kien}$ bock, ${ }^{17}$ Agostini, ${ }^{18}$ Jundell and Sjögren ${ }^{19}$ and many others showed that contrary to the previously current opinions, the normal heart, even after exhausting exercises, contracts considerably in volume. It follows from their work that acute dilatation of the healthy heart does not occur. Martius, quoted by Langstein, ${ }^{2}$ however, believes that cases of dilatatative weakness previously referred to react to exertion by an increase in heart size, and therefore concludes that these hearts are weak. According

15. Moritz: München. med. Wchnschr., 1907, No. 14; also 1908, No. 25.

16. Dietlen: Ergeb. der Physiologie, 1910; also München. med. Wchnschr., 1907, No. 10.

17. Kienbock, Selig and Beck: München. med. Wchnschr., 1907, No. 29.

18. Agostini : Ztschr. f. exper. Pharm. u. Therap., 1909, p. 159.

19. Jundell and Sjögren: Reviewed in Centralbl. f. inn. Med., 1912, No. 42, p. 1053. 
to Martius, this symptom is one of the most frequent in orthostatic albuminuria.

Schaps, ${ }^{12}$ relying on percussion, in an examination of sixteen cases of orthostatic albuminuria showing cardiovascular symptoms or signs, found only one case in which after exercise the heart seemed to have enlarged. This is of particular interest, in view of the fact that of the thirty-five cases described by him, twenty showed pathological heart findings (murmurs, arhythmia, accentuation of the basic sounds, instability of the pulse).

Neumann ${ }^{20}$ in eight cases of dilatative weakness, two of which had albuminuria, found by percussion that after stair-climbing the hearts increased in size.

Table 2.-Showing Heart Size Before and After Exercise in Cases of Orthostatic Albuminuria*

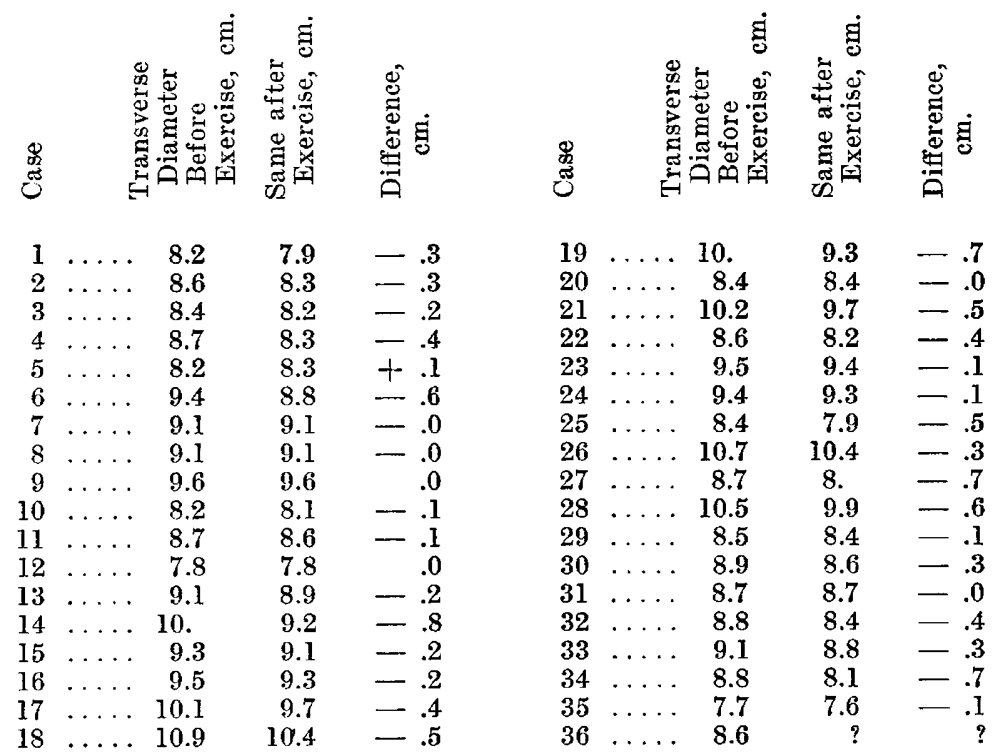

*This chart shows the heart-size before and after exercise. As in chart one the first fifteen cases are those with cardiovascular symptoms or signs.

The work of these observers is, however, not beyond criticism, since they relied for the determination of heart size on percussion only. We have been unable to find records of any orthodiagraphic heart examinations before and after exercise, either in cases of orthostatic albuminuria or in cases of dilatative weakness, and consider such an examination absolutely necessary for a conclusive determination of the question of dilatation after exercise. Such examination we have carried out. The exercise consisted in rapidly running up and down 160 steps, which

20. Neumann: Jahrb. f. Kinderh., 1900, lii. 
always resulted in considerable fatigue. The children were then immediately examined on the fluoroscope and orthodiagraphic tracings made under exactly the same conditions and position in which the tracings had been made before exercise.

Table 2 shows in parallel columns the transverse heart diameters in our thirty-six cases before and after exercise. It will be seen that in twenty-two cases the heart became distinctly smaller, while in the rest of the cases it remained unchanged or practically so. In no case did the heart become larger after exercise, not even in the children showing subjective or objective cardiac symptoms. These results definitely prove that the cardiac symptoms in this undoubtedly clinically distinctive group must find an explanation elsewhere than in the altered heart size, possibly in some disturbance in the vasomotor system.

It is noteworthy that although none of the hearts increased in size, thirteen of them failed to grow smaller. ${ }^{21}$ (We have included those which diminished only $1 \mathrm{~mm}$., as this was practically no change in heart size.) The failure of these hearts to contract after exercise is the more remarkable and is indicative of some abnormality of heart action, in view of the experience of Moritz that the hearts of youthful individuals and of those who are not accustomed to hard work, show the greatest amount of contraction. The exact significance of this fact we are not in a position to state; it may be looked on as an evidence of abnormal cardiac response, as healthy hearts quite regularly show a distinct diminution in size after exercise.

Various explanations have been advanced to account for the discrepancy between the increased size of the heart as shown by percussion and the actual findings as shown by the more objective methods. Herz, ${ }^{22}$ Romberg, ${ }^{23}$ Hoffman $^{24}$ and other authors have cautioned against the fallacy into which one is easily led, especially in cases of overacting hearts where the force and transmission of the apical impulse to the left, or as some describe it, its "irradiation," give the impression of cardiac enlargement. One is more prone to make such an error in cases with narrow, flat chests in which the heart has perhaps assumed a position absolutely nearer to the axilla because of lessened capacity of the thorax, and in which for the same reason the apex-beat has acquired a more lateral position in relation to the nipple. In addition, on exertion, with its resultant dyspnea, a transitory emphysema is produced whereby the diaphragm is pressed downward, pulling with it the apex of

21. In the estimation of heart size we have utilized the transverse diameter of the heart rather than the superficial heart area, as recommended by Moritz and Dietlen, owing to the errors inherent in the latter method.

22. Herz: Med. Klin., 1903, p. 778.

23. Romberg: Deutsch. med. Wchnschr., 1908, No. 47.

24. Hoffman: Kongress f. inn. Med., 1902, xx. 
the heart, thus creating the impression of enlargement, which is in fact only a displacement. These observations have special point in connection with orthostatic albuminuria, in which all observers who have used the $x$-ray for determination of heart size have without exception failed to find the heart enlarged, as opposed to those who by percussion frequently found the opposite. A concrete example in one of our cases will illustrate this liability to error:

Case 4 is a boy aged 14 years, tall, rapidly growing, with the flat, narrow chest which we have found so frequently in these cases, and which appears to be accentuated at puberty. Careful examination shows an overacting heart, a somewhat diffuse apical impulse, heaving in character, the left border percussing one finger outside the nipple line.

Such a heart might on purely clinical grounds be considered enlarged. An orthodiagram, however, reveals a heart normal in shape and size, but one which, owing to the narrowness of the chest, appears to occupy more space than is allotted to the heart in a chest of normal capacity; it therefore appears nearer the axilla, the heart being relatively too large for the thorax. Exactly similar conditions obtain in Case 8, a tall narrow-chested 10-year-old girl. The same explanation will apply to our finding so many small hearts; they are absolutely smaller for the height of the child, but relatively to the narrow chest they are normal in size.

\section{THE JUVENILE HEART}

It appears, therefore, that the foregoing results fail to disclose any evidence of cardiac enlargement in the great majority of cases. The few exceptions, however, to one of which reference was made in an earlier part of this article, are worthy of careful consideration, because they illustrate a definite heart type which, both as to morphology and function, stands in marked contrast to the rest of our cases. These are Cases 9,17 and 18.

Although only one of these (Case 18) shows orthodiagraphically a definite enlargement of the heart, there is undoubted evidence of left ventricular hypertrophy in all of them. Viewed on the fluoroscopic screen one is immediately impressed by the deliberate forcible pulsation of the left ventricle, by the rounded blunt apex and by the transverse position and oval shape which the heart has assumed (see Fig. 1 and compare with Fig. 2). These are all classical signs of left ventricular hypertrophy, combined in Case 18 with moderate dilatation. What is the significance of these changes in heart action and shape?

Under the name of "Wachstumshypertrophie" or juvenile heart, Krehl ${ }^{25}$ has described a type of case in which an enlarged heart occurs at or about the age of puberty, in the absence of nephritis or other

25. Krehl: Nothnagel's System, xv, 391. 
usual cause of left ventricular hypertrophy. In a large series of boys he was able to find a number in whom the heart was enlarged to percussion. In others in whom no enlargement was demonstrable, there was distinct evidence, however, in the heaving impulse and in the accentuated basic sounds, of left rentricular hypertrophy. In those cases in which the apex impulse was not heaving, although the heart percussed beyond the nipple, it was assumed that dilatation predominated over hypertrophy. Some of these cases had subjective symptoms, others had none, but in Krehl's experience their presence in every instance was associated with the heart changes described.

Our three patients above referred to, only one of whom complained of any subjective symptoms, correspond well to the Krehl type. They

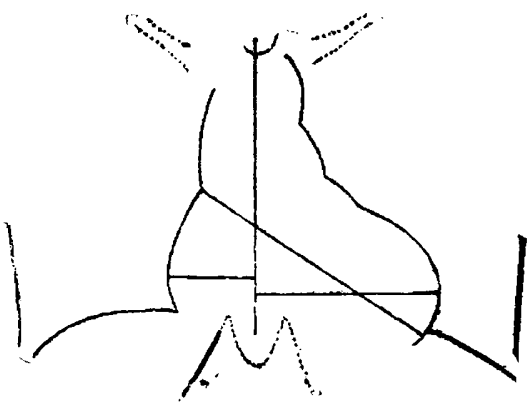

Fig. 1

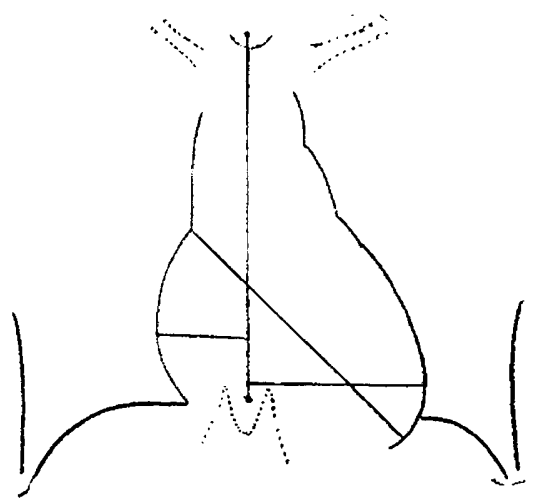

Fig. 2

Fig. 1.-Orthocardiogram of "Juvenile Heart." Transverse diameter $1.5 \mathrm{~cm}$. greater than normal. Shows transverse position, rounded apex, and deliberate, powerful pulsation characteristic of left ventricle hypertrophy.

Fig. 2.-Orthocardiogram of normal heart.

comprise a group in which probably only transitory heart changes occur, dependent on the disproportionate development of the circulatory organs and the rest of the body. In some cases this leads to an efficient hypertrophy; the heart being equal to the increased demands made on it. In others this hypertrophy is insufficient and subjective symptoms develop.

We are still more assured that these three cases correspond to the juvenile heart of Krehl, from the observations of Schwartz. ${ }^{20}$ The latter has made orthodiagraphic tracings of these hearts and insists that the fluoroscopic appearance above described is characteristic of this condition, and that by this means only can it be definitely diagnosticated. This is a point worthy of emphasis. By the ordinary methods of heart

26. Schwartz: In von Jagic's Handbuch der Herz und Gefässerkrankungen, Vienna, 1912, p. 436. 
examination the pure hypertrophy without cardiac enlargement in these cases might easily be overlooked, whereas the above-described characteristic heart silhouette effectively decides the diagnosis.

\section{EXAMINATION OF HEART RATE AFTER EXERTION}

All who have written on the subject of orthostatic albuminuria are agreed that in the cases characterized by cardiovascular disturbances, the most constant feature is the variability of the pulse, its so-called "lability" (instability). By this term (German "Labilität") is understood the tendency of the pulse to become much more rapid and poor in quality after very slight exertion. In cases showing this phenomenon, after simple exercise, as running up and down a few flights of stairs, it may be impossible to count the pulse at the wrist, owing to its extreme rapidity and smallness. In its most marked form, change in posture

Table 3.-Pulse Rate Recumbent, Standing and After Exercise in Cases of Orthostatic Albuminuria*

\begin{tabular}{|c|c|c|c|c|c|c|c|}
\hline $\begin{array}{l}\text { Case } \\
\ldots \\
\ldots \ldots \\
\ldots \ldots\end{array}$ & $\begin{array}{c}\text { Pulse } \\
\text { Rate in } \\
\text { Recumbent } \\
\text { Position }\end{array}$ & $\begin{array}{l}\text { Pulse } \\
\text { Rate } \\
\text { Stand- } \\
\text { ing }\end{array}$ & $\begin{array}{l}\text { Pulse } \\
\text { Rate } \\
\text { after } \\
\text { Exercise }\end{array}$ & $\begin{array}{l}\text { Case } \\
\ldots \ldots \\
\ldots \\
\ldots\end{array}$ & $\begin{array}{c}\text { Pulse } \\
\text { Rate in } \\
\text { Recumbent } \\
\text { Position }\end{array}$ & $\begin{array}{l}\text { Pulse } \\
\text { Rate } \\
\text { Stand- } \\
\text { ing }\end{array}$ & $\begin{array}{c}\text { Pulse } \\
\text { Rate } \\
\text { after } \\
\text { Exercise }\end{array}$ \\
\hline 1 & 68 & 72 & I24 & 16 & 72 & 80 & 144 \\
\hline 2 & 78 & 80 & 100 & 17 & 68 & 72 & 136 \\
\hline 3 & $\ldots$ & 92 & 184 & 18 & 120 & 120 & 148 \\
\hline 4 & $\ldots$ & 96 & 160 & 20 & 112 & 124 & 156 \\
\hline 5 & $\ldots$ & 76 & 72 & 22 & 76 & 88 & 84 \\
\hline 6 & $\ldots$ & 100 & 152 & 23 & 84 & 100 & 88 \\
\hline 7 & $\ldots$ & 86 & 128 & 25 & 130 & 100 & 96 \\
\hline 8 & 88 & 100 & 108 & 26 & 80 & 84 & 100 \\
\hline 9 & $\ldots$ & 88 & 132 & 27 & 80 & 80 & 160 \\
\hline 10 & $\ldots$ & 104 & 144 & 30 & 120 & 120 & 120 \\
\hline 11 & 80 & 84 & 148 & 31 & 88 & 96 & 132 \\
\hline 12 & $\ldots 96$ & 120 & 172 & 32 & 80 & 112 & 150 \\
\hline 13 & $\ldots 100$ & 104 & $?$ & 33 & 80 & 88 & 96 \\
\hline 15 & $\ldots 140$ & 140 & 195 & 34 & 80 & 80 & 168 \\
\hline
\end{tabular}

*Cases 1 to 15 are those which show cardiac symptoms or physical signs.

from the recumbent to the upright is said to result in a disproportinate rise in pulse-rate. To this symptom Thomayer gave the name "orthostatic tachycardia." Fischl ${ }^{13}$ found this instability to be an almost constant symptom, the pulse becoming smaller and more rapid by 25 to 30 beats, while Pelnar ${ }^{27}$ in sixteen cases was able at times to note an actual doubling of the pulse-rate. The effect on the pulse of the change of position from the horizontal to the upright is of special interest, because the albuminuria in these cases is so closely related to posture.

In Table 3 in the first column are given the pulse-rates in the reclining position. The rates resulting from a change to the upright position are seen in the next column. These figures show in the first place

27. Pelnar: Centralbl. f. inn. Med., 1905, p. 1025. 
that practically all the patients have approximately normal heart-rate when resting. The increase in rate on standing in the entire group varied between 0 and 32 (average $\%$ ). In the cases showing cardiovascular disturbances the increase varied from 0 to 24 (average 7 ). It will be seen that the cases showing symptoms differ in no wise from the remainder of the group of albuminurics. We have as a control examined the pulse-rates in ten perfectly healthy normal children 9 to 14 years of age, and found that the rate after changed positions was increased from 0 to 16 beats (average 8.4); in other words, slightly greater increase than in albuminurics. The increase in rate in our cases of albuminuria can therefore in no manner be considered excessive.

There are also numerous figures available for comparison in the literature: Dietlen ${ }^{28}$ in adults finds a normal variability of 8 to 40 beats, with an average of 18; $\mathrm{Guy}^{29}$ found a range of 4 to 44 and Shapiro ${ }^{30}$ 10 to 30 beats. It is therefore evident that our cases do not show any marked instability on change of posture. We have no doubt that unusual environment and the nervousness attendant on it, which we have taken pains to eliminate, can easily lead to error, as those hearts which at rest are unduly rapid show a proportionate increase on change of posture.

In the third column of Table 3 are tabulated the pulse-rates after exercise, which consisted in running up and downstairs, as noted before. The average increase in the cases with cardiac disturbance is 48 beats per minute, whereas, in the remainder the pulse-rate increased but 22 beats per minute. Results such as this would at first glance seem to point clearly to an abnormal irritability of these hearts and would seem to correspond well with the description given by the Germans to cases of pulse instability. However, when we examined the pulse-rates in perfectly normal children used as controls, we were much surprised to find that in them the increase in rate even exceeded that occurring in the orthostatic albuminuria cases, the healthy children showing an average increase of 50 beats per minute. Mere numerical increase in pulserate, therefore, cannot be taken as a criterion of instability in these cases.

From all the foregoing it might be suspected that our cases are in reality not of the same class as described by Martius as dilatative weakness, since we have shown that both as to heart size and pulse-rate our results are not in accord. However, when we take into account the character of the pulse before and after exertion, and especially when we compare the pulse with the cardiac action, both as evident to inspection and to the $x$-ray, we are impressed by the fact that our cases and those of Martius are the same. A large percentage of our patients after run-

28. Dietlen: Deutsch. Arch. f. klin. Med., 1909, xcvii.

29. Guy: Guy's Hosp. Reports, 1838.

30. Shapiro: Wratsch, 1881 (quoted by Dietlen). 
ning the stairs presented a characteristic picture of extreme fatigue and dyspnea. The pulses, which had previously been fairly strong, became weak and thready, so that in several instances the pulse could not be counted at the wrist. At times irregularity of the pulse also occurred. Not only was the apex impulse in many of these children with weak pulses extremely forcible, but the $x$-ray revealed markedly overacting hearts. This paradoxical condition of pulse and apex, which has been so frequently emphasized by European observers, therefore appears to be a characteristic symptom of this condition.

\section{EXAMINATION OF THE SHAPE OF THE HEART}

Aside from the information we have acquired concerning the size and functional capacity of the heart, $x$-ray study of our cases has revealed some interesting features concerning heart shape. It is well known from

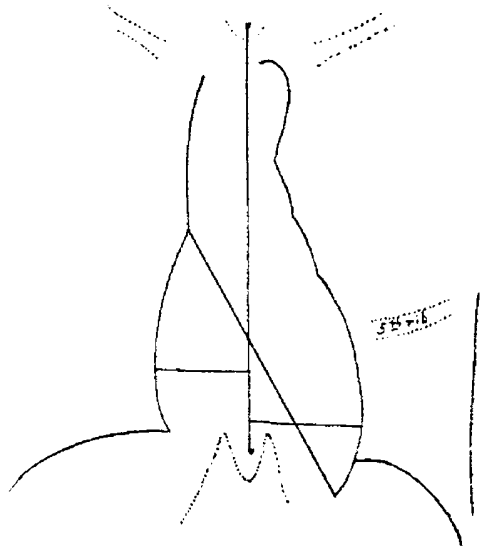

Fig. 3.-Orthocardiogram of "Drop Heart." Transverse diameter $8.8 \mathrm{~cm}$. Normal is $12.5 \mathrm{~cm}$. Note position of fifth rib.

the works of Veith and Reyher ${ }^{31}$ that the commonest form of the heart silhouette in childhood is that of an obliquely placed oval (Fig. 2); less commonly hearts of a rounded shape occur; and still more rarely the heart assumes either a transverse or a vertical position. The study of the heart shape in our cases shows in quite a number a striking deviation from this normal type. This abnormality consists in the tendency that the hearts show to assume a more median position in the chest, the apex of the organ appearing relatively lower, thus causing a vertical position of the heart axis. This gives the heart a drawn-out, narrow appearance, which, coupled with the elongation of the great vessels, results in a distinctive heart picture which has been aptly termed by the Germans the drop heart (Tropfenherz). This condition (Fig. 3), or one closely

31. Reyher: Jahrb. f. Kinderh., 1906, Ixiv. 
approaching it, we have found in ten of our cases, about 30 per cent., contrary to the report of Fischl, ${ }^{13}$ who was unable to find such hearts in cases of orthostatic albuminuria.

The drop heart has for many years been well known to the Germans, especially through the writings of $\mathrm{Kraus}^{32}$ by whom it has been associated with narrow-chested individuals, showing the neurasthenic habitus, who reveal various stigmata of constitutional weakness in which the heart is supposed to participate. Our findings, therefore, of such a large percentage of vertical or drop hearts is of particular interest, in view of the fact that it occurs in the very type of child which Martius has characterized as constitutionally weak.

\section{CONCLUSIONS}

Reviewing briefly the results of our investigations, we believe the following conclusions are warranted:

1. In a series of cases of orthostatic albuminuria selected at random, it will be found that a considerable number present evidence of relative cardiovascular insufficiency.

2. These symptoms, in the great majority of cases, are not associated with any hypertrophy or dilatation of the heart. On the contrary, the heart is in many cases smaller than normal; nor does it show any gross evidence of weakness as dilatation after exercise, an explanation suggested by previous investigators.

3. Although the hearts do not dilate after exercise, a considerable number of them fail to become smaller under these conditions. This failure to contract may perhaps be looked on as a restriction of the field of cardiac response.

4. The condition known as the juvenile heart or "Wachstushypertrophie" occurred three times in our cases and can be distinctly recognized.

5. The conception of pulse or heart instability must be restricted to a tendency of the pulse to become smaller and impalpable after exercise, a condition which we have found very common.

6. In 30 per cent. of the cases we have found hearts of the drop type, especially associated with other stigmata of constitutional maldevelopment.

In conclusion we wish to express our thanks to Dr. Leopold Jaches of the $x$-ray department of Mount Sinai Hospital for numerous courtesies extended to us during the course of our work.

54 West Ninety-First Street-122 West One Hundred and Eighteenth Street. 1906.

32. Kraus: Med. klin., 1905, No. 50; also Gedenkschrift für von Leuthold, 